Bevan, W.J. and Nolan, L., 2019. Barriers for renewable technology in commercial buildings. In: Sandanayake, Y.G., Gunatilake, S. and Waidyasekara, A. (eds). Proceedings of the $8^{\text {th }}$ World Construction Symposium, Colombo, Sri Lanka, 8-10 November 2019, pp. 116-124. DOI: doi.org/10.31705/WCS.2019.12. Available at: https://2019.ciobwcs.com/papers

\title{
BARRIERS FOR RENEWABLE TECHNOLOGY IN COMMERCIAL BUILDINGS
}

\author{
W.J. Bevan ${ }^{1}$ and L. Nolan ${ }^{2}$
}

\begin{abstract}
Policies within the United Kingdom (UK), such as the Renewable Energy Strategy, demand the construction sector to adopt renewable technology within buildings. Moreover, as commercial buildings are responsible for $14 \%$ of the total UK carbon emissions, building professionals are required to integrate renewable technology within these properties to assist the targets. Despite the policies, the UK renewable technology uptake remains low. Within this context, existing literature identifies the barriers to the adoption of renewable technology in buildings. There are few studies, however, concerning the current uptake of renewable technology in commercial buildings, in addition to little detail of solutions to the barriers experienced by the construction sector. A study was conducted to investigate the integration of renewable technology in UK commercial buildings. Data collection consisted of a literature review, a survey involving 30 construction professionals and two semi-structured interviews with an engineer and a programme manager. Findings evidenced a range of social, economic, and technical barriers for the adoption of renewable technology in buildings. Primary data results support concerns of the financial cost associated with the technology, along with greater detail to explain the barriers associated with awareness, a lack of experience and knowledge of renewable technology options for integration within commercial buildings. Finally, in contribution to theory, results evidence similar findings to existing literature published over 10 years ago, which indicates the need for future research to study solutions to the barriers of renewable technology adoption in commercial buildings.
\end{abstract}

Keywords: Commercial Buildings; Renewable Technology; Renewable Technology Barriers; Sustainable Buildings.

\section{INTRODUCTION}

To aid the strict carbon emission reduction targets within the United Kingdom (UK), there are a number of strategies in place to encourage the generation of renewable energy. The key policies include the Non Fossil Fuel Obligation (NFFO), the Renewables Obligation (RO) (Parkes, 2012) and the UK Renewable Energy Strategy (HM Government, 2009). As a result of the strategies, which demand $30 \%$ of electricity and $12 \%$ heat generation from renewable energy by 2020 (HM Government, 2009), pressures are placed on the construction sector to integrate renewable technology within buildings. More specifically, as commercial buildings contribute to $14 \%$ of UK carbon emissions (PIA, 2016), the construction sector is required to recognise the potential for renewable technology adoption within these properties. Moreover, to enhance the uptake of renewable

\footnotetext{
${ }^{1}$ School of Computing, Engineering and Mathematics, WSU, Australia, w.bevan@westernsydney.edu.au

${ }^{2}$ Noel Lawler Consulting Engineers, Ireland, laura.nolan2010@gmail.com
} 
technology, financial incentives, such as the Feed-in tariff (FIT) and the Renewable Heat Incentive (RHI), have been implemented by government.

Despite the UK policies, renewable technology contributed to $22.3 \%$ of the UK energy market for power generation in 2015 and 4.6\% of heat in 2014 (REA, 2016), which highlights the need for progress towards technology adoption in order to meet the 2020 targets. In an attempt to provide insight on the lack of renewable technology integration in buildings, prevailing literature states a number of barriers to technology adoption. The barriers include, but not exclusive to, economic, political, social and technical challenges. The problem, however, concerns the few investigations that focus on the uptake of renewable technology for commercial buildings. It appears to be the case that a large proportion of investigations study technology uptake within residential properties.

To worsen the problem, literature on the topic of renewable technology integration in buildings along with associated barriers to technology integration, are slightly out of date. There are valuable insights on the subject and detailed barriers to explain the lack of renewable technology uptake by different shareholders, but the research is approximately 10 or more years out of date. Furthermore, there appears to be little detail of solutions to the challenges for renewable technology adoption in buildings.

This paper investigates the barriers for the integration of renewable technology within commercial buildings. The research is novel as it provides empirical evidence in relation to the uptake of renewable technology by the construction sector. In addition, the study aims to enhance existing theory through the identification and explanation of barriers for the adoption of renewable technology within commercial buildings.

The paper is structured as follows. First, prevailing literature on the subject is reviewed. Second, the research design and methods are detailed. Third, the results and discussion are presented. Finally, the conclusions and contribution to theory are provided, along with the limitations to the study and further areas for research.

\section{RENEWABLE TECHNOLOGY ADOPTION FOR SUSTAINABLE BUILDINGS}

\subsection{BARRIERS TO RENEWABLE TECHNOLOGY}

Current construction innovation literature provides valuable insights on the barriers to renewable technology integration in buildings. A barrier can be known as "man-made factors or attributes of factors that operate in between actual and potential renewable energy (RE) development or use" (Verbruggen et al., 2010: p. 852), which can be intentional or unintentional. The dominant barriers described in the literature are connected to social, economic and political barriers, in addition to the technology specific barriers. The boundaries between each classification, however, are not distinct.

\subsubsection{Social Barriers}

Social barriers are associated with a lack of awareness of renewable technology options available to citizens (Menz, 2005), in addition to a lack of information and knowledge provided to the public, which can be crucial in the early stages of technology uptake (Neuhoff, 2005). To worsen the problem, the lack knowledge among adopters can then lead to an improper use or inability to maintain renewable systems (Karakaya et al., 2015). 


\subsubsection{Economic Barriers}

The cost associated with technology adoption has been highlighted as the most significant barrier to the integration of RE projects (Balcombe et al., 2013). Economic challenges are primarily associated with either the initial capital costs or the payback periods for the renewable technology. High costs and long payback periods can hinder the desire for technology investment and current policies appear to be failing to address the barrier. Policies, such as the FIT, have been implemented to aid the expense of solar technology integration, a technology which is deemed to not be of profit without policy support (Karakaya, 2015). Moreover, the perception of cost appears to be a barrier. It can be the case where the initial expense of renewable technology installation is perceived high, or assumed far greater than the actual cost (Koinegg et al., 2013).

\subsubsection{Political Barriers}

In order to drive the uptake of renewable technology and help achieve its full potential, stable and consistent policy frameworks, in particular policies aimed at improving risk and reward associated with the technology, are required (Foxon et al., 2005). Government can promote investment in technology through appropriate financial support, guidance and understandable frameworks.

\subsubsection{Renewable Technology Specific Barriers}

To gain an understanding of the technical barriers to renewable technology adoption in buildings, previous investigations appear to link the technical barriers to the technology itself. As Table 1 (shown below) evidences, challenges can be unique to the individual renewable technology or the energy system adopted within buildings.

Table 1: Technology specific barriers

\begin{tabular}{ll}
\hline \multicolumn{1}{c}{ Technology } & \multicolumn{1}{c}{ Barriers (literature source) } \\
\hline Solar Energy & - The architecture of an area; limited space and roof tops in urban areas. \\
& - Lack of knowledge, improper use and insufficient maintenance. \\
& - Lack of appropriate management \\
& (Karakaya and Sriwannawit, 2015) \\
& - Negative public perception. \\
& (Solar Electric Power Association, 2002) \\
\hline Biomass & - Uncertainty of biomass resource availability. \\
& (Rourke et al., 2009) \\
& - Lack of knowledge in regard to the technology, surrounding policies \\
& (Foxon et al., 2005) \\
\hline Combined Heat & - Long payback periods \\
and Power & - Commercial risk. \\
(CHP) & (Foxon et al., 2005) \\
\hline
\end{tabular}




\subsection{SuStainable COMMERCiAL BUILdingS}

As commercial property in the UK accounts for $13 \%$ of the built environment (PIA, 2016), there is significant potential for the sector to contribute to carbon emission reduction targets. Furthermore, due to the increasing desire to describe UK commercial property as 'sustainable' (Rydin, 2014), there is greater encouragement to consider the integration of renewable technology within these buildings.

Existing studies highlight and suggest a diverse number of barriers to explain low levels of renewable technology adoption, which include social, political and technical. Much of the literature, however, is focussed on residential building and is out of date. There is a need for empirical evidence on the current uptake of renewable technology in commercial buildings, along with additional insight of the challenges to the adoption and integration of the technology.

\section{RESEARCH DESIGN AND METHODS}

In line with aims and objectives of the study, the research adopted a qualitative approach to the investigation. Both primary and secondary data were required for the investigation in order to understand the current problem surrounding renewable technology integration in buildings, in addition to gaining insight into the adoption of the technology in commercial properties. Prior to data collection, ethics forms were completed and submitted to the University Ethics Committee.

\subsection{Data Collection}

The data collection consisted of a critical literature review, a survey and interviews with professionals of the building industry.

\subsubsection{Literature Review}

Secondary data collection involved a critical literature review of current construction innovation literature. The prevailing literature offered insight into the existing barriers towards renewable technology adoption in UK buildings, along with guidance for the interviews with professionals of the building industry.

\subsubsection{Surveys}

Primary data collection consisted of a survey involving professionals of the built environment, which identified perceptions of renewable technology and barriers to technology integration in commercial buildings. As the research focus was commercial buildings, those professionals involved in the specification of renewable technology integration in commercial properties were selected. Purposive sampling was adopted (Kelley et al., 2003), where a specific group of building services consultant engineers were selected in order to survey participants that had an understanding of the renewable technology specification for commercial buildings. Due to the provision of real-time, upto date empirical data and the potential to produce a great deal of data in a short amount of time (Kelley et al., 20013), an online survey was the chosen method for the investigation. The survey questions were created based on the aims of the research by using an online tool, known as Survey Monkey. Surveys were circulated using a weblink, which allowed the specific sample of participants to complete the survey, along with participant anonymity. 


\subsubsection{Semi-structured Interviews}

A primary data collection also adopted semi-structured interviews with professionals of the built environment. Candidates were selected in terms of involvement in the design and specification of renewable technology integration in UK commercial properties. Participant 1, a consultant engineer, was selected as a large proportion of the survey responses $(63.33 \%)$ were completed by individuals in this job role. Participant 2, a manager of an NGO, was selected as a significant proportion of surveys suggested renewable technology adoption involved the client and developer understanding of the technology. Prior to interviews, an interview protocol was prepared and pretested. The interviews were carried out face to face and tape recorded. Following the interview, recordings were transcribed verbatim.

\subsection{DATA ANALYSIS}

The data collected was analysed in line with the aims of the research. Microsoft Excel was used to collate and display the survey responses for analysis, primarily the arrangement of answers in table and graphical format. To analyse the interviews conducted, content analysis was adopted (Bryman, 2016). Content analysis is referred to as a technique or research method adopted for the interpretation of data and identification of themes and patterns (Hsieh and Shannon, 2005; Bryman, 2016). Guided by the research aims and insight from the existing literature, the interview transcripts were studied for themes that emerged from the data.

\section{RENEWABLE TECHNOLOGY ADOPTION FOR COMMERCIAL BUILDINGS}

The investigation provided insight into perceptions of renewable technology from professionals within the built environment, along with empirical evidence to highlight the adoption and integration of the technology in commercial buildings. Respondents included consultant engineers $(63 \%)$, architects $(17 \%)$ and contractors $(10 \%)$, in addition to a programme manager and a BREEAM assessor. The survey and interviews evidenced diverse levels of understanding associated with the renewable technology from the variety of construction sector roles. In addition, the primary data emphasised the complexity surrounding the integration of renewable technology in commercial buildings, i.e. the variety of barriers stated by building professionals.

\subsection{TYPES OF RENEWABLE TECHNOLOGY}

The research suggests there is an uptake of specific types of technology within commercial buildings. The surveys, for instance, evidenced the most common features adopted for commercial buildings were lighting, mechanical ventilation with heat recovery (MVHR) and photovoltaic (PV) panels, which suggests consideration of fabric measures. This was also supported in an interview with the engineer who indicated the value of energy efficient measures and the 'fabric first' approach, by mentioning “...fabrics are becoming more energy efficient and certainly glazing needs to be really looked at..."

Following the selection of what can be known as fabric methods (e.g. LED lighting and MVHR), solar PV, solar thermal, air source heat pumps (ASHP) and biomass were the 
technologies most discussed in terms of integration for commercial buildings. As the engineer stated,

"[in terms of technology for commercial buildings] I probably just know the standard ones, such as [solar] PV, solar thermal for hot water, biomass and I am aware of wind turbines, but they are not very cost effective for commercial properties." In further support, the programme manager expressed, "we have case studies where a lot of our members have installed PVS... we have a really good one from ASHP where British land at regent's place removed their gas boilers and installed an ASHP and reduced gas consumption by about $80 \% \ldots$

\subsection{BARRIERS TO RENEWABLE TECHNOLOGY}

In regard to the adoption of renewable technology and its selection for commercial buildings, the results evidenced primary barriers associated with these technologies (see Table 2 below). The dominant barriers can be broadly classified as economic, social and technical barriers.

Table 2: Barriers to the adoption of renewable technology

\begin{tabular}{lc}
\hline $\begin{array}{c}\text { Survey response to barriers of renewable technology } \\
\text { adoption within UK commercial buildings }\end{array}$ & $\begin{array}{c}\text { Frequency of } \\
\text { respondents }\end{array}$ \\
\hline Cost & 26 \\
Lack of experience/knowledge/awareness & 8 \\
Financial return & 8 \\
Client/developer & 7 \\
Planning permission & 3 \\
Aesthetics & 1 \\
Design limitation & 4 \\
\hline
\end{tabular}

\subsubsection{Economic Barriers}

Findings evidenced a high level of concern, $87 \%$ of respondents surveyed, in terms of the cost associated with the adoption of renewable technology in commercial buildings. Within this context, cost was associated with the initial capital required for the technology and the payback period, once the technology has been adopted. These findings support the literature that state a primary barrier of renewable technology are concerns for the upfront costs and payback periods (Balcombe, et al., 2013). To further enhance the literature, this research suggested payback periods longer than 10 years were the issue. As stressed by the Senior Mechanical Engineer, for instance, “...the client will probably be reluctant to pay for something, especially when the payback is more than $5-10$ years."

\subsubsection{Social Barriers}

The surveys highlighted a large proportion of respondents were aware $(53 \%)$ or very aware $(40 \%)$ of renewable technology options for commercial buildings. The interviews, however, provided insight of renewable technology awareness by building professionals, as mentioned a "limited knowledge of renewables" (engineer) and "lack of understanding [of renewables] and knowledge of what is available" (programme manager). The building professionals provided greater insight into the challenges towards a lack of renewable technology knowledge and its integration in commercial buildings, which can be linked 
to additional barriers. The level of knowledge and awareness of the renewable technology, for example, in addition to further impact of the barrier, was captured during an interview with the programme manager, who expressed,

"there is also bad examples of combined heat and power and lack of understanding from the industry in having the people who are able to run them, commission them and operate them...they [renewable technology] are not being used appropriately, they've been oversized so not fit for purpose."

In greater support of the issues associated with understanding renewable technology adoption for commercial buildings, the engineer stated,

"a few years ago I did an exercise on biomass boilers...the reality of getting the pellets and trying to speak to people who understood what pellets were, trying to understand deliveries...renewable energy is a good thing, it just needs everyone to get more on board and make sure we know what is out there."

The findings highlight there is an awareness of renewable technology and attempts by building professionals to understand the technology most appropriate for commercial buildings. There is a contrast with the prevailing literature due to ideas surrounding a lack of awareness of renewable technologies (Menz, 2005). There are studies, however, that offer insight for technology awareness in terms of the public and building end-users, as opposed to building professionals. Despite the individuals being studied, results resonate with previous research that states there is a need to enhance knowledge surrounding the integration of renewable technology.

\subsubsection{Technical Barriers}

Finally, the results provided indication where issues the renewable technology itself acted as a barrier to its adoption within commercial buildings. This is different to the above where the technology was deemed as costly or not understood, but a challenge due to its integration within or on the commercial building. The concerns with the renewable technology itself was evidenced by the programme manager, who stated,

“...the concerns regarding the technology, they [real estate] will always look for case studies to make sure that anything they are installing is tried and tested and assured...they [the renewable technology] are not being used appropriately, they've been oversized so not fit for purpose, issues with the technology not running properly but then that is sort of expected for new technology..."

\section{CONCLUSIONS}

The investigation has highlighted the complexity associated with the adoption of renewable technology in buildings, in addition to empirical evidence of the uptake and challenges of technology integration within commercial buildings. Prevailing literature demonstrates a range of barriers for renewable technology uptake in buildings, in addition to issues specific to the type of technology. This research investigation supported the dominance of economic barriers towards the adoption of renewable technology in commercial buildings, in terms of initial capital costs and payback periods. The findings also evidenced a lack of technology awareness, understanding and experience in regards to challenges for the adoption of technology. Moreover, by discussing the barriers with construction professionals, the investigation extended existing ideas to highlight the potential wider impacts associated with limited awareness, knowledge and experience with the renewable technology. 


\subsection{CONTRIBUTION TO THEORY}

The research supports previous studies in terms of the barriers to renewable technology adoption. The dominance of economic barriers, for example, along with evidence of social challenges and an understanding of the technology. This study enhances the literature to investigate commercial buildings and further highlight the complexity associated with renewable technology awareness and understanding. Moreover, results evidence similar findings to existing literature published over 10 years ago, which indicates the need for future research associated with solutions to the barriers of renewable technology integration in commercial buildings.

\subsection{LIMITATIONS OF THE STUDY}

The empirical evidence was based on a small sample of building professionals from an online survey (30 responses) and 2 interviews. Although the participants involved in the study did have a range of job roles, it would be valuable to conduct primary research involving diverse job roles within the built environment. The lack of relevant literature was also a limitation within the study. It would be beneficial to access more recent studies to the barriers of renewable technology, particularly as the technology and policy frameworks are constantly evolving and being updated.

\subsection{FURTHER AREAS OF RESEARCH}

Further research within the area of renewable technology adoption in commercial buildings will involve a larger sample size of building professionals and a greater number of interviews. A study that expands the sample size to potentially include diverse roles of building professionals involved in the selection and integration of renewable technology, is proposed. By enhancing the sample size, the investigation may also provide insight into the solutions to the barriers identified towards technology adoption in commercial buildings.

\section{REFERENCES}

Balcombe, P., Rigby, D. and Azapagic, A., 2013. Motivations and barriers associated with adopting microgeneration energy technologies in the UK. Renewable and Sustainable Energy Reviews, 22(1), pp.655-666.

Bryman, A., 2016. Social research methods. 5th Edn. Oxford, UK: Oxford University Press.

Foxon, T.J., Gross, R., Chase, A., Howes, J., Arnall, A. and Anderson D., 2005. UK Innovation systems for new and renewable energy technologies: drivers, barriers and systems failures. Energy Policy, 33(1), pp.2123-2137.

HM Government. 2009. The UK renewable energy strategy. [Online] Available from: https://www.gov.uk/government/uploads/system/uploads/attachment_data/file/228866/7686.pdf [Accessed 11 February 2019].

Hsieh, H.-F. and Shannon, S. E., 2005. Three approaches to qualitative content analysis. Qualitative Health Research, 15(9), pp.1277-1288.

Karakaya, E. and Sriwannawit, P., 2015. Barriers to the adoption of photovoltaic systems: The state of the art. Renewable and Sustainable Energy Reviews, 49(1), pp.60-66.

Kelley, K., Clark, B., Brown, V. and Sitzia, J., 2003. Good practice in the conduct and reporting of survey research. International Journal of Quality in Health Care, 15(3), pp.261-266.

Koinegg, J., Brudermann, T., Posch, A. and Mrotzek, M., 2013. "It would be a shame if we did not take advantage of the spirit of the time" An analysis of prospects and barriers of building integrated photovoltaics. Ecological Perspectives for Science and Society, 22(1), pp.39-45. 
Menz, F., 2005. Green Electricity Policies in the United States: Case Study. Energy Policy, 33(18), pp.2398-2410.

Neuhoff, K., 2005. Large-scale deployment of renewables for electricity generation. Oxford Review of Economic Policy, 21(1), pp.88-110.

Parkes, R., 2012. Can the UK meet its renewable targets?. Renewable Energy Focus, 13(1), pp.24-27.

PIA (Property Industry Alliance), 2016. Property data report 2016 [Online] Available from: http://www.bpf.org.uk/sites/default/files/resources/PIA-Property-Report-2016-finalfor-web.pdf [Accessed 14 February 2019].

REA (Renewable Energy Association), 2016. Overview of UK's renwable energy growth [Online] Available from: http://www.r-e-a.net/blog/overview-of-the-uks-renewable-energy-growth-08-06-2016 [Accessed 10 February 2019].

Rourke, F. O., Boyle, F. and Reynolds, A., 2009. Renewable energy resources and technologies applicable to Ireland. Renewable and Sustainable Energy Reviews, 13(8), pp.1975-1984.

Rydin, Y., 2014. Sustainable Commercial Property, London: UCL Bartlett School of Planning.

Solar Electric Power Association, 2002. Solar Power Solutions: A business Case for Capturing Total Value, Annandale, VA: Global Environment and Technology Foundation.

Verbruggen, A., Fischedick, M., Moomaw, W., Weir, T., Nadaï, A., Nilsson, L.J.. Nyboer, J. and Sathaye, J., 2010. Renewable energy costs, potentials, barriers: Conceptual issues. Energy Policy, 38(1), pp.850861. 